\title{
Creative Management and Innovation
}

\section{Abstract}

Hana Janáková

Nowadays, entrepreneurship is determined how fast innovations or creativity can be incorporated into company activities. Creativity is mean constantly aspiring process of innovation and progress. Creativity and innovation management these days are important keys to any effort how to be success in business world. Forces of creativity in company or in entrepreneurship should be able to provide innovation and contribute to solve problems. The new idea are often accepted as the main activity of creative management and the vision, strategy, goals or ideas are understands like equipment of creativity. Implementation of new ideas - innovation is the main activity of creative management. Visions, strategies, objectives and ideas are seen as tools of creativity.

Because of differences in innovation process between EU and USA, innovation processes in EU are directly supported via framework programs. Currently FP7 is active, but new process for innovation called Horizon 2020 is under preparation. Last FP7 program is oriented for cooperation between science oriented organizations (universities) and SME, while future Horizon 2020 will be oriented for excellence science, competitive industries and better human society.

In paper are presented real examples of companies/projects within the EU, including Slovakia. Three types of projects are compared. While project SAFER is supported by EU FP7, project Volvo Vision 2020 and Logomotion project are not supported and are commercial projects. Slovak project is supported by private investor. All projects are different, but have common line - to manage innovation process and implement it in real life. To manage innovation teams located around the world required creative concept in management.

Keywords:

creative management, innovation, creativity, creative manager, creative process

\section{JEL Classification: L26, 031, 032}

\section{Introduction}

Creative management is the study and practice of management, drawing on the theories of creative processes and their application at individual, group, organizational and cultural levels. When capitalized, we are applying the term 'Creative Management' in a formal sense to distinguish a fifth stage in the practice of management, emerging from the historical theories and practices of management from earlier stages. When uncapitalized, the term is used in a less formal sense to refer to a management style 
which will become associated with the emerging fifth stage of management. Historically we can distinguish five stages of management history (Fangqi, 2007).

Stage 1: 19th-20th Century: Rational Management (USA Fordist and Tayloristic contributions provide Production line efficiencies)

Stage 2: Early 20th Century: Incremental innovations (Japanese Total Quality approaches with structural sub-groupings provide further efficiency gains)

Stage 3: Mid-20th Century: Humanistic experiments (European and American efforts to achieve individualized motivation within organizations and for welfare of employees)

Stage 4: Late 20th Century: Organizational Creativity (Institutional efforts to achieve more creative organizational practices and results).

Stage 5: 21st Century: Creative Management (Globalized efforts achieve better diffused and integrated knowledge transfer of creative theories and practices)

Creative Management is emerging currently from the processes of Stage 4, and offers focus for revitalizing management theory and practice. Imitation and adoption through mimesis of the practices associated with successful companies will accelerate the transition to Stage 5.

In Europe, research on creativity and innovation in business followed the rise in interest in the United States. The journal Creativity and Innovation Management was founded in 1992 and was followed by the formation of The European Association of Creativity and Innovation (EACI) in 1994, with its regular international conferences and proceedings.

Creativity has the capacity to break conventions, the usual way of thinking, to allow the development of a new vision, an idea or a product. The creativity is closely linked to the nature of artistic contribution as expressed in art or cultural productions.

Process of creative management goes hand in hand with innovations. Usually innovation is automatically associated with new technologies. Innovation is often measure by the amounts of money spent on research and development. R\&D spending is of course a proxy for innovation (Molnar, 2008). It has the advantage that it can be measured quite precisely, but innovation is something quite different. Doing things smarter is a more intelligent way - which often means getting more for the same input or less. This sometimes involves using technology, sometimes it does not. Innovation also can be changing processes, changing the way we do things. Technological change is now very fast, but often meets a deep inertia among social institutions. Innovations determining the competitiveness have not only technological dimension, but also the organizational and personal one - the quality of human resources is extremely important for the profitability and the development of an organization. Managers of many successful companies often are ashamed to admit that they cannot understand the reasons for the success of their corporations (Wojnicka, 2010). Usually however, these are companies largely based on a variety of networks. In the case of the complex technology, a network includes a dozen of companies and different governmental agencies and organizations of the non-profit sector, such as universities. In addition, such a network, integrating various skills, must not be static. Innovative networks are continually evolving. 
The new nature of the innovation process makes it necessary to adapt not only to its standards of measurement, but also the law. For example in the United States of America in the 1980s the anti monopolistic law was changed so as to enable the creation of consortia of research and development between companies (Henry, 2008, Dytr, 2009). In a later period it appeared that companies must obtain a permit for a consortium, if it relates to companies from the same industry. In the European Community in 1985 there was introduced a block exclusion from the article 85 of the Treaty of Rome setting out the rules of competition law for certain categories of consortia of research and development (Wojnicka, 2010). Many studies point at the positive relationship between cooperation and innovation and competitiveness of businesses. In Canada on average 1/3 of the industrial companies participates in the various agreements for cooperation. A greater percentage of cooperating companies is among large companies $-37.2 \%$ than the small and medium-sized companies $-28.3 \%$. At the same time, among large companies there are more innovative companies (89.6\%) than the average for the entire industrial sector is $(82.3 \%)$. The cooperation is of crucial importance for an increase in creativity and innovation in the UK. From the research based on the internet survey conducted by the Confederation of British Industry (CBI) in the year 2000 it appears that $75 \%$ of 350 companies surveyed cooperated with other companies, researchers, consultants, research institutes or private research companies over the last 3 years (2000-2003) (Wojnicka, 2010).

The focus of this report is on creativity and innovation in systems and organizations rather than creative individuals. The report develops as creativity techniques and innovation can be applied to enhance the creative potential of a task. What creativity techniques with innovations can be applied depends on the type and characteristics of a pocket of creativity.

\section{Innovation system}

Companies are a critical element in the innovation system, and their health determines the competitiveness of countries and social wellbeing. In the view of the new theory of economic growth developed by such researchers as Kenneth Arrow, or Robert Lucas, knowledge is the primary factor in determining productivity.

The concept of the innovation system emphasizes the cooperation as well as the flow of technology and information and various relationships and interactions between individual elements as a condition conducive to the success of the innovation process (Bilton, 2007).

OECD gives, the following definitions of innovation systems derived from analyses on national innovation systems:

- the network of public and private sector, whose activities and interrelations initiate, import, modify and expand new technologies;

- the group of institutions which both together and individually contribute to the development and diffusion of new technologies, and creates a skeleton, within which the governments formulate and implement the policies influencing the innovation process; the system of interconnected institutions that create, store and transfer knowledge, skills and tools that define new technologies. 
In the broader view, the innovation system consists of the following elements (Pulsecky, 2011, Konsti-Laasko, 2012, Bogers, 2012):

1. The institutions that generate knowledge and innovation:

- companies,

- institutions intermediary in the transfer of technology, knowledge absorbing round-the-business services (KIBS),

- public education and the area of research: universities and scientific institutes (public, private)

- public authority to the extent of how the research inspire and introduce innovation.

2. The Channels of knowledge transfer: interactions and interdependencies between the institutions

- direct innovative relationships (imply the direct activity in the research and development area or cooperation for a specific innovation)

- interactions between companies - the vertical and horizontal linkages: the joint creation of new knowledge, applied research and experimental development - cooperation in the field of R\&D, shared patents, joint publications; interactions with the KIBS; interactions within the company between different departments and stages of the innovation process,

- the interactions between companies and the public area of $R \& D$, i.e. the world of science and the intermediary institutions

- joint patents, research, publications, etc.,

- indirect innovative relationships (less associated with a particular innovation, and increasing overall innovation potential of companies)

- the market diffusion of technology, i.e. the acquisition of technology identified as machinery, buying external knowledge/ know-how,

- mobility of workers and transfer the so-called tacit knowledge i.e. the hidden, non-material knowledge resulting from the experience and learning process, identified as employees,

- other: interactions with the environment.

3. Environment

- the market - the demand for innovation,

- the public authorities and their policies - legislation: the protection of intellectual rights, pro-innovative policy etc.,

- a system of employees education (system of learning and training),

- the infrastructure for innovation - the financial, communication, transport system in the particular region.

4. Characteristics

- openness - relations also with innovation centers and the knowledge from the outside system

- behavioral culture at a company level, the attitudes of public authorities, local community the institutions characteristics resulting from the "roots" in the given environment, historically formed specificity of a given system 


\section{- completeness - the presence of all necessary elements.}

Innovation systems are tested at various levels. The majority of analyses are conducted on national innovation systems, since it is considered that the characteristics distinctive to individual nations most affect the distinctness of the innovation process in companies: the type and number of institutions and their behavior (Hemlin, 2011).

\section{Innovation and creativity}

Innovativeness gives rise to paradoxes. It should be pointed out that one of the main features typical for start-up and operation of business is to take a risk. Even greater risk emerges when an innovative business is established. On the other hand, an entrepreneur who wants to engage in an innovative business, while taking the risk, has to assure, sometimes even to a quite substantial degree a feeling of security for hired employees. In other words - the employees need the safety buffer to activate their unfettered creativity that can bring innovative effects (Bissola, 2011).

Creativity, either of an individual or a group, should lead to a certain goal. What happens when it does not (failure to provide economic value) and why? Some premises explaining this situation lead to considerations about the condition of human capital and social capital, as well as the relations between these two elements. Social capital is one of the most important factors deciding the level of economic development (Stoneman, 2010).

Joseph Schumpeter (Schumpeter, 1939) was the first to point out the connection between innovativeness and entrepreneurship, claiming that it is the role of an entrepreneur to create innovation. This, in turn, requires a vision and commitment, yet when one observes the reality of numerous economies, it seems obvious that entrepreneurs for whom innovativeness is in fact a basis for operation are in minority. It should be kept in mind that an entrepreneur does not operate in a void, but within a surrounding of various entities that should and can provide support. Therefore, the task of an entrepreneur is not to invent (to create an invention), but to assure that the acquired knowledge is transformed into a market product. The results of research conducted recently using a sample of European enterprises prove that entrepreneurs play an important role in the process of commercializing knowledge, and the higher the entrepreneurship level in a society (number of enterprises), the higher the probability that the created knowledge will be transformed into an innovative product or service (Block, 2009). Research also indicates that the failure to catch up with Europe of the USA or other leading economies in the field of innovativeness originates in "knowledge leaks", unlike diffusion, "knowledge spill-overs", which happens in economies occupying higher ranks in the innovativeness ranking. Today, most important of issues that are related to the development of knowledge on innovation mechanisms include (Shane, 2009):

- changing the conviction that innovation means primarily high technology

- raising awareness that innovations pertain not only to business. Innovations and innovative behavior can be created in public institutions and non-governmental organizations

- indicating various levels of innovative measures that are assigned to particular groups, i.e. entrepreneurs as the main actors in commercialization, employees of 
enterprises as the main creators of facilitations at the organization level, consumers/users being the key entities defining the nature of innovations

- raising awareness about the process-like nature of innovativeness, which begins once the knowledge has been acquired and subsequently goes through next stages and finally becomes an innovation. The stage of passing from knowledge to its use is critical, and at this stage the process is most often discontinued or suspended.

\section{EU - world differences}

The power of the United States is created by innovative immigrants. The society of the United States arose from immigrants and still relies on their continuous influence. Contrary to what might seem when we hear about the millions of illegal newcomers finding their way to the USA by the green border, the United States are also, and in a very consistent manner, similarly green program, i.e. "Green Card". The right of permanent residence shall receive only those immigrants who meet the specific expectations and who prove during the test of their behavior that they could adapt themselves to the specificities of a culture of entrepreneurship prevailing in the United States.

The famous study carried out in 1999 by University of California, Berkeley showed that between the years 1980 and 1998, more than 24\% of new companies in the Silicon Valley has been settled by the Chinese and Indians.

On the other hand, the study of the Duke University in 2006 shows that 10 years later, in the years 1995 to 2005, this percentage has increased twice - to $52.4 \%$, and throughout the country aliens created $25.3 \%$ of all the new technological and industrial companies. In the particular states, the outcome was even higher, e.g. in California 39\% in New Jersey $38 \%$ or $30 \%$ in Georgia and 29\% in Massachusetts. Besides the Chinese and Indian, the most numerous group of businessmen-immigrants are visitors from the United Kingdom, Taiwan, Japan, but also from Cuba, Colombia, Brazil, Venezuela, Guatemala and Israel. The study of the Duke University showed also that in 2006 throughout the United States, the authors of $24.2 \%$ of the international patent applications filed in 2006 were foreigners (Samborski, 2011).

Therefore, highly skilled immigrants are one of the most powerful attributes in the USA. They have their share of the economy, create jobs and lead in innovation. They are the driving force in the development of highly technological economy and have a substantial share of the national intellectual property rights. In the States there is a general awareness that the continuation of the highly competitive position in a globalised market requires from the state to raise the best and the most skilled professionals. The realization of this national goal is helped by the constantly improved immigration policy.

We have to point, that situation in last five years is changing in patents area. Currently China is producing such numbers of patents like other states around the world together. US have Silicon Valley, Asia have Taiwan, but EU?

Until recently, the EU began to understand that for the maintenance of the socio-economic level of their countries the Europeans will need new immigrants as economic partners, in the light of the current demographic situation, the Lisbon Strategy and the future of the Union may crumble into ruin if a responsible immigration policy throughout the Union is not changed (or rather - if it is not invented). There must be an important place for a recruiting strategy of highly qualified workers and entrepreneurs, 
and their integration with the communities of the member countries of the Union. The European Union has recently adopted a number of provisions aimed at coordinating policies and instruments for immigration and integration of the member countries, setting as the primary objective the need to establish clear and fair criteria for admitting citizens of the third world countries, in the same way as the other countries that traditionally are the immigrants target - the USA, Canada or Australia.

\subsection{EU research program - step to innovation}

An important part of the European Commission's budget is devoted to encouraging innovation, research and development (R\&D, and in particular the exploitation of new technology resulting from scientific research. These resources allow research to move faster, and help European businesses to get ahead of world competition. European support also ensures that research efforts are not wasted - European researchers work together instead of duplicating the same work in different parts of Europe. European Commission R\&D programs are grouped together in so-called 'framework programs' covering several years of activity. These ensure that the different actions planned are coherent and harmonious. CORDIS provides regular updates on their execution. These policies concern researchers and scientists who are working on tomorrow's technologies. They also concern the majority of European businesses whether large or small. Ultimately they concern every European citizen, as we are all increasingly affected by technological developments in our daily lives. CORDIS is the Community Research and Development Information Service for Science, Research and Development, supports this process through its services. The Seventh Framework Program for research and technological development (FP7) is the European Union's main instrument for funding research in Europe. FP7, which applies to the years 2007-2013, is the natural successor to the Sixth Framework Program (FP6), and is the result of years of consultation with the scientific community, research and policymaking institutions, and other interested parties. Since their launch in 1984, the Framework Program has played a lead role in multidisciplinary research and cooperative activities in Europe and beyond.

FP7 has some key differences to earlier EU research program, including:

- Increased budget - the FP7 budget represents a 63\% increase over FP6, which means additional resources for European research. It is also a strong political message to the EU Member States, which have committed themselves to increase research spending.

- Focus on themes - a strong focus on major research themes (e.g. health, ICTs, space, etc.) within the largest component of FP7 - Cooperation - makes the program more flexible and responsive to the needs of industry.

- European Research Council (ERC) - the first pan-European agency for funding research, the newly created European Research Council, aims to fund more high-risk yet potentially high gain European research at the scientific frontiers.

- Regions of Knowledge - FP7 established new Regions of Knowledge that bring together the various research partners within a region. Universities, research centers, multinational firms, regional authorities and SMEs can all link up and strengthen their research abilities and potential.

- Risk-sharing finance - a risk-sharing finance facility has enhanced backing for private investors in research projects and improved access to loans from the European Investment Bank (EIB) for large European research actions. 
- Joint Technology Initiatives (JTIs) - a user-driven follow-up to the European Technology Platforms (ETPs), the JTIs are a new concept that brings together different partners to take on objectives that cannot be reached via the 'Calls for Proposals' approach. JTIs specifically address those areas of research activity where enhanced collaboration and considerable investment are essential to long-term success.

For period 2014-2020 new framework program is under development and is called Horizon 2020 (Horizon, 2012). Time-line for Horizon 2020 started in 2011. In mid 2012 final calls under 7th Framework Programme for Research is bridge gap towards Horizon 2020. By the end of 2013 adoption of legislative acts by EU Parliament and Council on Horizon 2020 is expected. In 1.12014 Horizon 2020 will starts with first calls.

EU FP7 is widely used around EU for innovation. In Slovakia small and medium size enterprises get a chance to obtain needed resources. They fight with problems how to make the project right. They are not able to do good project, but they don't have money to pay for it. However this is very good chance for them how to obtain needed finance (Sobeková Májková, 2011).

\section{European examples of creative management and innovation}

We can describe how real creative management and innovations have been implemented in European companies.

\subsection{SAFER}

Project SAFER (Ollila, 2011) is Sweden open innovation arena involving 22 partners from academia, industry and government conducting joint research on traffic and vehicle safety. The organizations include large actors such as AB Volvo, Scania and Autoliv and small technology organizations. SAFER provides office space and meeting rooms for the partners. Its explicit vision is: 'to enable Sweden to reach world leading competitiveness and to provide new countermeasures to considerably reduce both the number of traffic accidents and the number of fatalities and serious injuries'. Its aims are 20-fold growth in project money turnover in 10 years. The research involves work on active safety (pre-crash), passive safety (crash and post crash) and traffic safety analyses, and is multi-disciplinary in that it encompasses many different areas from vehicle dynamics and communication technologies, to biomechanics and human behavior. Field operational tests are conducted in the accident analysis area. Via project SAFER is total 68 subprojects on-going, of which 13 is directly funded by EU FP7.

Project SAFER is an interesting case because it differs from the innovation actors previously studied in the literature. It enables innovation by providing a physical space for the collaborating partners and has a proprietary vision to become a world leader. SAFER was launched in 2006. Five years later, there are about 170 people working on SAFER projects as part of their daily operations, while still being employed by their respective companies. SAFER has a board with nine members (including the chairman), mainly from industry. The board has overall strategic responsibility for the centre, monitors the project portfolio, decides on the start of projects and academic courses, can request projects to be initiated in areas not covered by the current project portfolio, and 
appoints the operating manager. A group of the participating partners proposes people for consideration as board members.

The activities of SAFER are organized around four research areas (pre-crash, crash, post-crash and traffic safety analysis). The projects within each research area are managed by a coordinator with the support of an expert reference group. The reference groups enable active researchers (from university, industry, research institutes, public authorities) to co-operate and create an innovative research environment. There are 12 competence areas (for instance road user behavior and biomechanics) each of which has an assigned leader.

Thematic analysis of the interview transcripts identified three types of challenges: one in the interface between SAFER and the partner firms, one between the partner firms and one in relation to the role of SAFER. These issues and illustrative quotations are presented below.

SAFER has the ambition to become world leader in traffic safety, a goal to which the partner organizations are expected to contribute. This vision is complementary to the goals of some of the partner organizations, and similar to that of others, which results in a competitive situation. Despite an often explicit desire to contribute to the joint vision of SAFER, company representatives expressed the difficulties this implies in practice. For instance, SAFER's success is perceived as threatening for one partner organization.

People involved in projects at SAFER come from different organizations. It is often unclear how the work in SAFER projects is valued by these organizations. For instance, the work in the arena is sometimes considered additional and not contributing to career development in the home organization. This is illustrated in a quote from a university researcher who is the project manager of a SAFER project including members from several partner organizations.

Launching a SAFER project requires a board decision. However, being a partner in a collaborative arena implies dealing with a variety of decision systems, to launch projects. SAFER needs to be convinced by the proposal as well as the participants' home organizations. If these organizations are part of a large international group, decision processes can be extensive and time consuming.

\subsubsection{Challenges for SAFER Partner Organizations}

There are also challenges related to the interfaces between the partner firms. Since SAFER is constituted mainly by partner firms, problems among partners have a major effect on the open innovation arena and are an important concern for its director. At SAFER, people are continuously encouraged to share knowledge. The assumption is that if everyone gives, everyone gains. There are different reasons for participating in SAFER, which are apparent in how the different companies relate to each other in the collaboration. Some want to contribute to the overall knowledge generation while others go to great lengths to create benefit for themselves. This can cause difficulties in projects.

SAFER provides an opportunity for the partner organizations to collaborate with many other organizations, including competitors. However, partner organizations are not entitled to participate in every project. The teams are decided project by project, and there are no guidelines for project team make-up. Sometimes a partner organization considers a project not very interesting because the 'right' people are not involved. 


\subsubsection{Challenges in Relation to the Role of SAFER}

The third type of challenges relates to the role of SAFER. SAFER is described officially as a joint research unit: The Vehicle and Traffic Safety Centre at Chalmers is a joint research unit where academy, industry and authorities co-operate in the design of future vehicle and traffic safety systems'. Despite this description, many interviewees reported not knowing what SAFER 'is', and therefore they do not know how to relate to it. Perceptions of SAFER vary, causing confusion in aspects such as expectations, accountability and affiliation. This means that many participants struggle with feeling part of SAFER, and only identify themselves with their home organizations. They report difficulties in knowing who are considered to be SAFER people

The first type of challenge, in the interface with partner organizations, includes possible competition between the arena and its partner organizations. This is related to the specificity of the open innovation arena, which has proprietary vision; this is not a challenge in the context of an open innovation intermediary where the explicit purpose of the actor is to support firms in their innovation attempts.

The second type of challenges, related to the collaboration among the partner organizations, includes the variety of motives for participating in the arena.

The third type of challenge is related to the role of the arena. For people participating in projects, spending much time in the arena's physical offices, understanding the arena is crucial. If it is not clear to people, they will try to make sense of the arena based on their experiences in their home organizations. Hence, the arena may be perceived as an organization with all the expectations of processes and routines supporting the daily work that this interpretation entails. This has important implications for the management of the open innovation arena.

To handle competing visions, the arena manager needs to initiate a discussion with the partner organizations about how to align visions to create the prerequisites for collaboration. This probably will require a series of one-to-one meetings with each partner organization, where the arena director meets the person responsible for the innovation strategy of the different partner organizations. To mitigate the challenges related to launching projects, the decision processes need to be aligned, for instance to an understanding of how proposals should be formulated to support more efficient decision making outside the arena. The challenges of the emerging matrix organization need to be addressed by establishing a clear contact between the arena and the manager of the persons working on the arena projects. The manager of an open innovation arena must also handle problems related to collaboration among partners by supporting the development of an open culture. This can be done by organizing activities beyond the projects, to give partner organizations joint experiences to relate to and by ensuring that joint office space supports the activities of the arena. It is important to make the arena an attractive place to work in. To avoid the arena being wrongly perceived as an organization, the manager needs to clarify the arena's distinctive characteristics. Such clarification will help to reduce uncertainty and set reasonable expectations on the arena. It can be achieved through continuous communication about the role of the arena and inviting partner organizations to discuss their contributions.

\subsubsection{Aspects of creative management of SAFER project}

The creativity management of project SAFER is based on establishing new type of scientific research consortium. Consortium consists on strong economical partners 
(Scania, Volvo), university, small research companies and state institutions. Creativity depends on connecting diverse interest entities whose entire project was different. On one side better and safer trucks on other side legislation and on third side economic profit.

Merging of different aims require creativity of managers - to create concept investigators - researchers, academic staff, company managers (Volvo, Scania) and state employees.

The centre for this project was established in university because of biggest creativity of academic staff.

\subsection{Volvo Company project Vision 2020}

The automotive industry worldwide (Börjesson, 2011) is in deep trouble, due not only to decreasing sales but also to the need for radical change and innovation required to meet the environmental challenges that are emerging in our modern society. The point has been reached where it has become evident that action was required long ago to redirect production towards more environmentally friendly and sustainable offerings. If car manufacturers are to survive, they need now to strive continuously towards more efficient product development processes using new technologies, novel designs and specially developed features. These needs require new creative management to change old rules in industrial companies. Improvements have tended to focus on areas such as performance, fuel consumption, safety, comfort and driver information, all areas that have improved exponentially. Automotive firms have developed their capabilities to innovate within this paradigm, resulting in 'more-of-the-same' products, while competition has become ever fiercer due to structural changes in the marketplace, intense brand competition, stricter regulation, growing fragmentation and shorter product lifecycles. All these changes are subjecting car manufacturers to extreme pressure - to excel in the execution of current capabilities and to develop new organizational capabilities in areas that are unfamiliar to them while at the same time revising their overall strategic direction. In general terms, organizational capabilities signify what an organization is (or is not) able to do for instance, organizational capabilities have been seen as the abilities of firms to deploy their available resources to achieve the desired end results, describes the firm's core capabilities as the set of knowledge that provides competitive advantage. According to her, these capabilities have four dimensions: employee knowledge and skills; technical systems; the managerial systems that guide the knowledge creation and control processes, and the values and norms associated with these processes.

\subsubsection{Project Achievements in Brief}

The Vision 2020 ((Börjesson, 2011) project was brought to an end in early 2009 in the context of a major re-organization of Volvo Cars under new creative managers (CEO and others). New creative management project was decided to establish a new organizational unit - Long Range Strategy and Innovation - to deal with long-term strategic issues and creative innovation. The more detailed agenda for the unit is still under development, but should allow a more structured way of dealing with developing capabilities to achieve innovativeness. It could be argued that institutionalization of the project is a major creative achievement. 
The objective of the Vision 2020 project was to build the new creative organizational capability in process of developing car to break away from the prevailing incremental approach to innovation and to 'innovate differently'. In particular, Volvo Cars wanted to be able to create and launch offerings that encompassed safety and eco-environmental improvements, to increase attractiveness and the willingness of customers to pay for a 'common good', but without relying on external incentives related to greening. Thus, the overarching aim was to learn how to creatively innovate so that the offer could be profitable while the level of both private and common good could be increased, which translated in the aim to develop Volvo Cars' creative capabilities for innovation. Vision 2020 was a bottom-up initiative, but it was well anchored in parts of Volvo Cars' top creative management team and overall responsibility lay with the Vice-President (VP) of Brand.

The Vision 2020 project was small in terms of staffing. The core team initially was three people and was reduced to two in 2007, one of whom was replaced during the latter part of 2008. However, throughout its two-and-a-half year life, the various activities of this core team had the support and involvement of many people from different parts of the Volvo Cars organization. The aim of the Vision 2020 project to develop the creative company's organizational capability was focused on two explicit objectives: first, to be experimental creative and explore different methods of and approaches to creative innovation, and second, to systematically develop a different mindset for the creative decision makers - at all levels. The project defined four routes to achieving the first objective of being experimental and exploring new approaches:

1. Defining targets. Defining what needed to be achieved in order to overcome societal and ecological constraints and thus define the problem as well as part of the solution.

2. Defining technology pathways. Participating in studies on alternative energy consumption and provisions for the future, in order to choose from technologies that fitted with future paths.

3. Innovating differently. Experimenting with combinations of different expertise in the processes of idea generation (especially to the bundling of private and common goods and combining different perspectives), and creative product development.

4. Conducting small-scale market tests as a way of learning (business model development). To address the second objective of developing organizational competence and cognition, that is, influencing those involved in creative decision making, the project team identified a need for continuous development of competences, but without originally specifying or knowing how this could be achieved. It became obvious that this objective was a dominant and time-consuming part of the project.

\subsubsection{Experimenting with Alternative Creative Methods}

In terms of activities and processes, the Vision 2020 project had a strong focus on experimentation. The project started with some experimental activities related to how to creatively innovate, based on multi-disciplinary workshops designed to promote ideas and concept development, drawing on design-based theory and external knowledge sources. Central to the project was that Volvo Cars needed to develop alternative activities to enable it to innovate differently, or as a member of the core project team expressed: We need to create an organizational ability to earn profit on our core values of safety and environment. That is [we need] to learn how to creatively innovate differently. 


\subsubsection{Experimenting with Ideas Generation in Terms of Focus and Approach}

The Vision 2020 project was based on hands-on or 'learning-by-doing'. The aim was to experiment with relatively small innovations (such as car subsystems), then to capitalize on that experience to persuade creative management to fund a larger experiment (potentially a car). The insights developed would be disseminated through the company in order to contribute to the development of creative organizational capabilities. This dissemination was enabled by the contributions of an extended team linked to the project that included key members of the organization.

The project kicked off with an ideas and concept-generation workshop series to define desired attributes. The series involved various stakeholders from different internal disciplinary and functional backgrounds in the organization coming together to form temporary taskforces. The outcomes of the workshops were drawn on for a subsequent series of idea-generation creative exercises based around environmentally friendly concepts.

\subsubsection{Aligning with and Breaking Into Existing Arenas}

Another aim of the project was to align with the intentions of existing initiatives or processes that were focused on future production. For example, the project was aligned to the ongoing Premium Brand work and an Alternative Fuels Strategy initiative aimed at winning acceptance of building capabilities ideas.

Important is, that project has participated in the international five-year Living Tomorrow project (2007-2012). This involved some 50 partner companies, among which Volvo Cars was the only car manufacturer. Living Tomorrow is providing a vision of how people will live, work and travel in the future. The fundamental idea of Living Tomorrow is to create physically visible, groundbreaking creative innovations that are shown in Brussels. The Vision 2020 project participated in mutual learning from its involvement with this endeavour.

\section{Collaboration with New External Partners}

Vision 2020 was involved in co-operation with external partners, including universities, in areas such as consumer behaviour and energy studies, which were knowledge domains that were not part of Volvo Cars' expertise at the time. In addition to creating a knowledge network, the collaborations were aimed at expanding knowledge in certain areas where internal expertise was lacking, in particular knowledge related to green offerings.

One of the core project team members expressed an ambition in interview: 'We want to develop an "aha!" effect, to trigger recognition and subsequent learning in the organization'.

\subsubsection{Aspects of creative management in Vision 2020 Volvo project}

Creative management in project Volvo Vision 2020 is based on creativity of subjects, not economically connected to Volvo Company - leader of project. This concept in development of new products in automotive industry is not typical. Development connection existed only in the case of personal ar economics connection relationships between companies. Development of automobile industry is usually done by external company but for the first time Volvo used for design of concept of new product. 
The Volvo study also points to an urgent capability that, although well known, is too often neglected: creativity of management. Study shows that without the explicit and consistent support of top management, capabilities development will not progress, but there are few in-depth discussions of this in the literature on innovation capabilities. In the case of Volvo Cars and the Vision 2020 project, it soon became apparent to the core team that the main problem was a lack of strategic direction in the company (and a lack of strategic development work). This made it difficult for the project to achieve a pioneering impact on the organization. Despite their efforts, the team members were unable to gain the leverage required without the simultaneous development of a strategic dimension and management's acknowledgement of the need to develop new capabilities. Strategic direction can be formulated in terms of the implementation of strategic rules. At Volvo Cars, during the time of the project, there were few explicit rules, and those that were in place worked to reinforce the organization's existing behaviour of following the same paths, rather than enabling the required strategic change. Since top management was not providing a clear strategic direction for the organization, the members of the organization applied their own interpretations about what needed to be done and acted accordingly. The aim of the project was to renew the way that the firm worked and this required a much stronger link to strategy.

Last important note is, that Vision 2020 project was integrated into another international project Living Tomorrow, where Volvo is the only automotive company.

\subsection{Logomotion mobile payment}

We can describe Slovak research-development project - Logomotion (Logomotion, 2012) mobile payment. This is the biggest Slovak research development project with private Slovak investor. Logomotion is developing a comprehensive secure micro SD card based mobile payment solution supporting contactless payment at a POS terminal with a consumer's existing mobile phone. This solution is compatible with open payment scheme standards such as Pay Pass ${ }^{\mathrm{TM}}$ and Pay Wave. Logomotion's secure micro SD card [LOGOMOTION PAY CARD] has a miniature antenna for contactless payment. The consumer will be able to make offline payments for small amounts of 1-5 EUR and also make normal online payments for larger amounts. This project has been established in 2009. The LOGOMOTION PAY CARD contains a payment chip, a microprocessor, flash memory, a frequency chip and a miniature antenna. The card architecture is designed to meet payment industry security standards.

Logomotion's proprietary antenna design has been tested by the Institute of Radiofrequency and Microwave Engineering of Leibniz University in Hannover, Germany. Their Measurement Certificate shows that Logomotion's miniature NFC antenna design performs up to ten times the minimum level set by the payment industry's specification for contactless payment. The card comes with payment and other applications developed by Logomotion. Third party applications, such as for transit ticketing or merchant loyalty can be stored in flash memory. The card also contains normal memory space for the consumer to use for storing songs, photos, videos and so on.

Solutions for paying at a contactless POS terminal in a shop are often designed for either small offline payments (usually less than 10 EUR) or for larger online payments. 
Logomotion's mobile payment solution includes an innovative payment process hosted on the LOGOMOTION PAY CARD which:

- is simple for the consumer and merchant;

- can be processed with existing payment infrastructure

- enables offline or online authorization as called for in payment industry business rules.

Logomotion has patents pending for this innovative payment technology. For some consumers, remembering a PIN to use at the POS terminal in a shop is an inconvenience. Logomotion has a patent pending for this innovative payment technology.

Project has been established like former existing technological concept of OPEN NT (Slovak) company. Connection of technical engineers with Slovak investor leads to establishing small team with mixed manager control of people from university area, international business area and industry area. Development process is splited between small research teams, which cooperate under manager control. Teams are located in Slovakia, Czech rep. and Taiwan. Testing series should be produced in Taiwan, so manager's rule is strongly important to organize cooperation between partners.

We have to point, that this project has no publicity yet. There are three or four similar projects around the world, bus only two of them have a chance to be commercially successful. One of them is Logomotion project.

\subsubsection{Aspects of creative management}

Logomotion project is a special case: was established on green-field with aim to develop new technology wireless payment method independent on mobile phones producers. A specific feature in this case is that was established in Slovakia like small high-tech company without research employers, where management had to create a structure of creative research team, to find suitable researchers with technical experiences and mixed them within different countries. Each development team has to find solution for independent tasks (special chip design with security payment cryptography), design of high-frequency antenna embedded in communication unit for wireless communication.

Creative management is responsible for:

- General technical concept with respect of partial solutions

- Research team selection

- Organization of cooperation between teams

- Patents verification and validations

- Serial production preparations

- Visa/MasterCard validation and acceptation process

We have to point, that establishing and selecting research teams was the most difficult part of project, because of Logomotion has no experience within development of products in this field of area. Expected production/capacity which will be realized on Taiwan, is probably about 5 millions SD cards per month.

The beginning of testing process of mobile payment SD cards is planning in the first half of 2012, while a final production should be achieved at the end of 2012 . 


\section{Discussions}

Creativity management is used to describe alternative approaches to business processes such as strategy development and organizational change at the operational level, the development of new products and technological innovations and their introduction into practice. The paper is presented different cases of creative management with innovations in practice.

Case SAFER describes process of establishing consortium of large automotive companies, small research companies, universities and state institutions. For success of this project is necessary to find structure of cooperation, because of aim of all partners is different. Creativity and inventions are required in process of cooperation different teams. Project SAFER is specific. To manage, where high business companies, small research companies, universities and state institutions are connected together is difficult. Strong creativity how to connect university level thinking with business oriented companies and byrocratic state institutions is required. Currently the project is still successful and still functional. To get the most creativity in the project is centrally managed mainly from the universities.

Volvo Vision 2020 project is a special project to develop a new concept car with free new ideas for future collaboration with external partners. Difficulties may be to manage the project on interaction with other projects, for example - Living tomorrow. The development of entirely new product - a hybrid car is held in the new structure. External companies are members of the new team that was responsible for a new concept. But to manage this team is not easy. Volvo car used information from another project team member as Living tomorrow - and then the automobile design pursued with regard to the human body and the quality of life. Creativity management was to link human needs, quality of life and respecting the technical constraints.

Project LOGOMOTION Pay Card is a special case of high-tech project, based on a green field site with private investors. Management, as this kind of project requires creativity at all levels. MicroSD card payment will be certified by Visa and MasterCard. The certification process is under development. The card will be delivered to customer banks, like credit card. In an emergency bank IT operator can connect the card directly via GPRS/3G (mobile phone) and modify the data connection limit or block the card in case of theft.

From management point of view creativity of managerial staff is important with respect of so call "inside corporate blindness". Term "inside corporate blindness" we can use to describe situation, where managers cannot see problems inside company, cannot distinguish what is correct and what is not and are using old methods to managing company without needs to increase effectiveness of control of internal managerial and innovational processes. After long term managerial process mistakes of functional relations between departments, especially between technical development departments and strategic development departments can produce problems and results are sometimes catastrophic. Organizational problems inside company can results in bankruptcy. Last example is Kodak - world leader in photography. Kodak designed first world digital photo camera, but managerial concept with adaptation to new technology was not successful. Also Siemens Mobile division was not successful and finished their production, Ericson Mobile division formerly leader in mobile phone devices was unsuccessful and was sold out to Sony. Nokia - world leader in mobile phones is quarterly falling down. In computer business area are also know examples of DEC and Compaq. Sometimes managers are working with idea that "movement is important, not change". 
If we will analyze companies and realized projects, everything seems to be clear and easy. But in process of conceptual decisions, managerial role is important. To take final decision and responsibility for strategic solutions in innovations is sometimes hard. Managerial staff should be sensitive and creative to made correct decision and that is sometimes difficult. As classic says: "After the war, every soldier is general”.

\section{Conclusion}

Creativity in management is used to describe alternative approaches to business process, such as strategy formation and organizational change, and at the operational level to refer to new products development and technological innovation.

We have presented four different cases of creative management in practice. Creativity is not only the condition for innovation and, a core competitive factor in contemporary organizations. Creativity and creative management influences business processes and the way how conduct business process management (Brettel, 2011).

This paper described typical scenarios in which creativity impacts business processes and their management and presented exemplary strategies and actions that organizations apply to deal with the phenomenon of creativity to enhance process performance and quality of creative products. It is relevant and timely to take a closer look at the role that creativity plays within business processes and how it can be managed. Existent modeling techniques, tools of management and management practices may support some of the important creative aspects in this context. However, until now there is no comprehensive approach on how to manage creativity from a business process perspective. With this paper could to set the baseline for a discussion on the notion of the creativity-intensive process. Creativity and innovation are the fuel that will fire the dream of business success. They are the engines of action and of the ability to withstand the pains of growing a concern. Business building is very hard work but with a positive approach the tasks can become joyful.

\section{References:}

Bissola, R - Imperatori, B. (2011): Organizing Individual and Collective Creativity: Flying in the Face of Creativity Clichés, Creativity and Innovation Management, 2011, Volume 20, Number 2, pp.77-89 pp., Blackwell Publishing Ltd., ISSN 1467-8691

Bilton, Ch. (2007) Management and creativity: From creative industries to creative management. Blackwell publishing, Oxford: 2007. ISBN: 978-1-4051- 1996- 2, 175 pp.

Block, J.H., R. Thurik, H. Zou, (2009) What turns knowledge into Innovative Products?The role of Entrepreneurship and knowledge spillovers, Erasmus Research Institute of Management (ERIM), 2009,

Bogers, M., West, J. (2012): Managing Distributed Innovation: Strategic Utilization of Open and User Innovation, Creativity and Innovation Management, Volume 21 Number 12012 , pp. 61-75, Blackwell Publishing Ltd., ISSN 1467-8691

Börjesson, S.- ELMQUIST, M (2011): Developing Innovation Capabilities: A Longitudinal Study of a Project at Volvo Cars, Creativity and Innovation Management, Volume 20 Number 3 2011, pp.171-184, Blackwell Publishing Ltd., ISSN 1467-8691

Brettel, M., J. Cleven, J., (2011): Innovation Culture, Collaboration with External Partners and NPD Performance, Creativity and Innovation Management, 2011, Volume 20, Number 4, 253-272, ISSN 1467-8691 
Confederation of British Industry (CBI), 2001, 2002, 2003, Under-line Ref. Nr. 4

Dytr, Z.Střítelská, M. (2009) Efektivní inovace: Odpovědnost v managementu. Computer press, Brno: 2009. ISBN: 978-80-251-27771-1, 143 pp.

Fangqi, X. - Rickards, T. (2007): Creative Management: A Predicted Development from Research into Creativity and Management, Creativity and Innovation Management, 2007, Volume 16, Number 3, pp. 216-228, Blackwell Publishing Ltd., ISSN 1467-8691

Hemlin, S. - Olsson, L. (2011): Creativity-Stimulating Leadership: A Critical Incident Study of Leaders' Influence on Creativity in Research Groups, Creativity and Innovation Management, Volume 20 Number 1 2011, pp. 49-58, Blackwell Publishing Ltd., ISSN 1467-8691

Henry, J. (2008): Creative Management and Development, $3^{\text {rd }}$. Edition, Sage publications, London, ISBN-13 978-1-4129-2248-7

Horizon, (2012): Available from internet http://ec.europa.eu/research/horizon2020/index_en.cfm

Interakcje w procesie innowacyjnym jako czynnik konkurencyjności przedsiębiorstw, część 1, 2012. 4PM Project Management [online]. [wieved 25/05/2012]. Available from: http://www.4pm.pl/artykul/interakcje_w_procesie_innowacyjnym_jako_czynnik_konk urencyjnosci_przedsiebiorstw_czesc_1-37-54.html

Konsti-Laasko, S., Pihkala, T., Kraus, S. (2012): Facilitating SME Innovation Capability through Business Networking, Creativity and Innovation Management, Volume 21 Number 12012 , pp. 93-105, Blackwell Publishing Ltd., ISSN 1467-8691

Logomotion, (2012): Available from internet www.logomotion.eu

Molnár, P. (2008) Innovation management. EKONÓM, Bratislava: 2008. ISBN 987-80-225-283-4, pp.45-49

Ollila, S. - Elmqist, M. (2011): Managing Open Innovation: Exploring Challenges at the Interfaces of an Open Innovation Arena, Creativity and Innovation Management, Volume 20 Number 4 2011, pp. 273-283, Blackwell Publishing Ltd., ISSN 1467-8691

Pulsecky W. Z. (2011): Innovation and Competiveness, EAI, ISBN: 978-83-62214-02-0,

Samborski, J. (2011): INNOVATIVE IMMIGRANTS ARE THE SECRET OF THE SILICON VALLEY, EAI, ISBN: 978-83-62214-02-0,

Schumpeter, J., (1939), after: D.S. Landes, J. Mokyr, W.J. Baumol, The invention of enterprise. Entrepreneurship from Ancient Mesopotamia to Modern Ages, Princeton University Press 2010.

Shane, S. (2009): Why encouraging more people to become entrepreneurs is bad public policy, Small Business Economics, 2009, pp. 141-149,

Sobeková Májková, M. (2011): Analýza skúseností MSP s vypracúvaním projektov v kontexte s čerpaním finančných zdrojov z Európskej únie, Ekonómia a podnikanie, Vedecký časopis Fakulty ekonómie a podnikania PEVŠ, 1/2011, str. 57-63, ISSN 1337-4990

Stoneman, P. (2010) Soft innovation: Economies Product Aesthetics and the Creative Industries, Oxford 2010. ISBN 978-0-19-95-7248-9, str. 47-57, pp. 113-133

Wojnicka, E. (2010): Interactions in the innovation process as a factor of competitiveness of companies, Internet source:

\section{Ing. Hana Janáková,}

Đaneuropean University, Faculty of Economics and Business,

Department of International Business, Tematínska 10, 85105 Bratislava,

Slovak Republic, HJanakova@gmail.com 